\title{
Commentary \\ Positive end-expiratory pressure in acute respiratory distress syndrome: should the 'open lung strategy' be replaced by a 'protective lung strategy'?
}

\author{
Jean-Jacques Rouby ${ }^{1}$, Fabio Ferrari², Bélaïd Bouhemad ${ }^{3}$ and Qin Lu ${ }^{4}$
}

\begin{abstract}
1Professor of Anaesthesia and Critical Care, Head of Surgical Intensive Care Unit, Réanimation Chirurgicale Polyvalente Pierre Viars, Groupe Hospitalier Pitié-Salpêtrière, Assistance Publique-Hôpitaux de Paris, Université Pierre et Marie Curie of Paris - 6, 47/83 boulevard de l'Hôpital, 75651 Paris Cédex 13, France

${ }^{2}$ Research Fellow, Department of Anesthesiology, Faculdade de Medicina da Universidade Estadual Paulista Julio de Mesquita Filho, Botucatu, Brazil ${ }^{3}$ Praticien Hospitalier, Surgical Intensive Care Unit, Réanimation Chirurgicale Polyvalente Pierre Viars, Groupe Hospitalier Pitié-Salpêtrière, Assistance Publique-Hôpitaux de Paris, Université Pierre et Marie Curie of Paris - 6, 47/83 boulevard de l'Hôpital, 75651 Paris Cédex 13, France

4Praticien Hospitalier, Surgical Intensive Care Unit, Director of Research, Réanimation Chirurgicale Polyvalente Pierre Viars, Groupe Hospitalier PitiéSalpêtrière, Assistance Publique-Hôpitaux de Paris, Université Pierre et Marie Curie of Paris - 6, 47/83 boulevard de l'Hôpital, 75651 Paris Cédex 13, France
\end{abstract}

Corresponding author: Jean-Jacques Rouby, jjrouby.pitie@invivo.edu

Published: 11 December 2007

Critical Care 2007, 11:180 (doi:10.1186/cc6183)

This article is online at http://ccforum.com/content/11/6/180

(C) 2007 BioMed Central Ltd

See related research by Carvalho et al., http://ccforum.com/content/11/5/R86

\begin{abstract}
In patients with acute respiratory distress syndrome, positive endexpiratory pressure is associated with alveolar recruitment and lung hyperinflation despite the administration of a low tidal volume. The best positive end-expiratory pressure should correspond to the best compromise between recruitment and distension, a condition that coincides with the best respiratory elastance.
\end{abstract}

In an experimental study performed in piglets with oleic-acidinduced lung injury [1], Carvalho and coworkers provide evidence that high positive end-expiratory pressure (PEEP) is associated with alveolar recruitment and lung hyperinflation despite the administration of a low tidal volume (TV). In addition, the best compromise between recruitment and distension coincides with the greatest respiratory compliance, a result suggesting that the 'best' PEEP should be set according to respiratory mechanics. The present study enlightens as regards the safest and most efficient method for setting PEEP in acute respiratory distress syndrome (ARDS), and questions the classical view of 'keeping the lung open'.

\section{Aeration loss, recruitment and ventilator- induced lung injury: a critical reappraisal of classical concepts}

Mechanical ventilation, indispensable for keeping alive ARDS patients, can be harmful to the lung [2]. Experimental ventilator- induced lung injury (VILI), characterized by a nonspecific high-permeability-type pulmonary oedema, results from high TV rather than high airway pressures [2]. In the early 2000s, the concept of 'volutrauma' found a clinical application with evidence that the reduction of the TV in patients with ARDS was associated with improved survival [3].

Experimental studies performed on the atelectasis-prone lung lavage model demonstrate that high pressures applied to the respiratory system can reopen collapsed alveoli and restore normal arterial oxygenation [4]. In an ex vivo lung model of saline lavage, the use of high PEEP combined with a low TV was demonstrated to reduce histological VILI [5] and to reduce the resulting inflammatory reaction [6]. Following these studies, the concept that VILI and pulmonary biotrauma are caused by cyclic opening and closing of distal lung units became widely accepted. In parallel, Gattinoni and colleagues hypothesized that lung recruitment consisted of 're-opening collapsed alveoli' [7]. The sternovertebral gradient of lung aeration evidenced on juxtadiaphragmatic lung regions was ascribed to the 'collapse' of dependant distal airways caused by the increased lung weight. To prevent 'end-expiratory collapse', a PEEP equal to the vertical gradient of superimposed pressure is required.

This theory became widely accepted, and the actual vocabulary used by most investigators is faithful to the

ARDS $=$ acute respiratory distress syndrome; $\mathrm{FIO}_{2}=$ fraction of inspired oxygen; $\mathrm{PaO}_{2}=$ arterial oxygen partial pressure; $\mathrm{PEEP}=$ positive end-expiratory pressure; $\mathrm{TV}=$ tidal volume; $\mathrm{VILI}=$ ventilator-induced lung injury. 
concept that recruitment consists of 'opening collapsed lung units' by applying a pressure above a supposed 'critical opening pressure'. VILI, termed 'atelectrauma', is considered to result from tidal 'opening and closing' of distal lung units and fully recruiting the lung as an essential prevention. In order to 'fully open the lung', a high peak inspiratory pressure is applied followed by a high PEEP in order to maintain a $\mathrm{PaO}_{2} / \mathrm{FIO}_{2}$ ratio $\geq 450 \mathrm{mmHg}[8]$.

If this classical concept is true, patients with ARDS should benefit from high PEEP combined with recruitment manoeuvres. Unfortunately, a recent randomized multicentre trial failed to demonstrate any benefit on the duration of mechanical ventilation and on mortality [9]. Interestingly, three articles in the early 2000s had questioned the validity of classical concepts [10-12], warning against the indiscriminate administration of high PEEP to every ARDS patient [13]. Doubts over classical concepts came from a critical reappraisal of the lung morphology characterizing experimental models of ARDS [10], and from the analysis of data from computed tomography examination of the whole lung, not only from juxtadiaphragmatic regions [14].

\section{Mechanisms of ventilator-induced lung injury differ according to experimental models}

Studies supporting the concept of a 'collapsed lung' were performed on models where natural surfactant is removed from the alveolar space by repetitive sequences of bronchial lavage/drainage [15]. In such models, atelectasis resulting from distal airway collapse is largely predominant over inflammation and oedema [16]: the lung weight does not substantially increase and the decrease in lung aeration results from end-expiratory collapse [17], whereas lung inflammation and alveolar oedema remain moderate [18]. Of course, endexpiratory collapse is constantly observed when lungs are removed from the rib cage, whether normal or injured. This model is easy to perform and highly reproducible. Unfortunately, the model's clinical relevance is limited to surfactant deficient lungs of premature neonates and to initial lung injury resulting from tidal hyperventilation.

The oleic-acid-induced lung injury model used by Carvalho and colleagues [1] is radically different, and mimics more closely histopathological disorders observed in human ARDS: the lung weight markedly increases, the massive loss of lung aeration results from the filling of the alveolar space by haemorrhagic oedema, alveolar expansion is preserved (the alveolar gas is replaced by haemorrhagic fluid) and lung inflammation is overwhelming $[19,20]$. PEEP-induced lung reaeration probably results from the displacement of the gas-liquid interface distally in the alveolar space, and it is unlikely that PEEP acts by exceeding hypothetical 'threshold opening pressures'.

The experimental type of lung injury directly impacts on the mechanisms of VILI. Following lung lavage, the distal lung is collapsed because of surfactant depletion and VILI essentially results from tidal opening and closing of distal lung units (shear-stress). High PEEP appears 'protective' against VILI. In oleic-acid-induced and endotoxin-induced lung injuries, distal lung units are expanded, are filled with haemorrhagic or proteinaceous oedema, and are infiltrated by inflammatory cells [21]. VILI mainly results from overstretching of aerated parts of the lung (volutrauma), and high PEEP may further contribute to VILI by increasing hyperinflation, as elegantly demonstrated by Carvalho and colleagues [1].

\section{Hyperinflation and recruitment in ARDS patients at end-inspiration and expiration}

Hyperinflation and recruitment are simultaneously observed in a majority of ARDS patients in different lung regions at endinspiration and expiration.

Data obtained from computed tomography of the whole lung have shown that a PEEP produces not only end-expiratory reaeration of nonaerated parts of the lung (recruitment), but also simultaneous end-expiratory hyperinflation of aerated pulmonary areas [22-24].

Recruitment and hyperinflation also occur simultaneously at end-inspiration in different lung regions in ARDS patients ventilated with a low TV [25]. The risk of VILI increases when the proportion of normally aerated lung decreases. Carvalho and coworkers confirm that complete lung reaeration is obtained at the expense of significant hyperinflation of a normally aerated lung [1]. This finding indirectly confirms that alveolar recruitment does not correspond to the 'pop up of collapsed distal lung units', a mechanism that should theoretically result in a sudden drop of airway pressure and in the 'protection' of normally aerated lung regions [26].

\section{Lung-protective ventilator strategy compromises between recruitment and hyperinflation}

A lung-protective ventilator strategy should not only reduce the TV but should also apply a PEEP corresponding to the best compromise between recruitment and hyperinflation.

Based on human studies demonstrating that a high PEEP induces both alveolar recruitment and hyperinflation, it has been proposed to limit the PEEP to around $10 \mathrm{cmH}_{2} \mathrm{O}$ in patients with a focal loss of lung aeration and to use other means for optimizing arterial oxygenation [12,13,27-29]. Carvalho and coworkers bring compelling evidence that the PEEP corresponding to the best compromise between recruitment and hyperinflation corresponds to the minimal respiratory elastance [1]. Such a result provides a bedside tool for clinicians to individually optimize the PEEP in ARDS patients, offering a safer lung protective ventilator strategy.

Following a pirouette, of which medical history is fond, the PEEP corresponding to the best compromise between 
recruitment and hyperinflation confirms and throws light on the results of a study performed 33 years ago demonstrating that the best PEEP is the PEEP associated with the best respiratory compliance [30].

\section{Competing interests}

The authors declare that they have no competing interests.

\section{References}

1. Carvalho AR, Jandre FC, Pino AV, Bozza FA, Salluh Jl, Rodrigues R, Ascoli FO, Giannella-Neto A: Positive end-expiratory pressure at minimal respiratory elastance represents the best compromise between mechanical stress and lung aeration in oleic acid induced lung injury. Crit Care 2007, 11:R86.

2. Ricard JD, Dreyfuss D, Saumon G: Ventilator-induced lung injury. Curr Opin Crit Care 2002, 8:12-20.

3. Ventilation with lower tidal volumes as compared with traditional tidal volumes for acute lung injury and the acute respiratory distress syndrome. The Acute Respiratory Distress Syndrome Network. N Engl J Med 2000, 342:1301-1308.

4. Barbas CS, de Mattos GF, Borges Eda R: Recruitment maneuvers and positive end-expiratory pressure/tidal ventilation titration in acute lung injury/acute respiratory distress syndrome: translating experimental results to clinical practice. Crit Care 2005, 9:424-426.

5. Muscedere JG, Mullen JB, Gan K, Slutsky AS: Tidal ventilation at low airway pressures can augment lung injury. $A m$ J Respir Crit Care Med 1994, 149:1327-1334.

6. Tremblay L, Valenza F, Ribeiro SP, Li J, Slutsky AS: Injurious ventilatory strategies increase cytokines and c-fos m-RNA expression in an isolated rat lung model. J Clin Invest 1997, 99:944-952.

7. Gattinoni L, Caironi P, Pelosi P, Goodman LR: What has computed tomography taught us about the acute respiratory distress syndrome? Am J Respir Crit Care Med 2001, 164: 1701-1711.

8. Papadakos PJ, Lachmann B: The open lung concept of mechanical ventilation: the role of recruitment and stabilization. Crit Care Clin 2007, 23:241-250, ix-x.

9. Brower RG, Lanken PN, Maclntyre N, Matthay MA, Morris A, Ancukiewicz M, Schoenfeld D, Thompson BT: Higher versus lower positive end-expiratory pressures in patients with the acute respiratory distress syndrome. N Engl J Med 2004, 351:327-336.

10. Hubmayr RD: Perspective on lung injury and recruitment: a skeptical look at the opening and collapse story. Am J Respir Crit Care Med 2002, 165:1647-1653.

11. Rouby JJ, Lu Q, Vieira S: Pressure/volume curves and lung computed tomography in acute respiratory distress syndrome. Eur Respir J Supp/ 2003, 42:27s-36s.

12. Rouby JJ, Constantin JM, Roberto De AGC, Zhang M, Lu Q: Mechanical ventilation in patients with acute respiratory distress syndrome. Anesthesiology 2004, 101:228-234.

13. Rouby JJ, Lu Q, Goldstein I: Selecting the right level of positive end-expiratory pressure in patients with acute respiratory distress syndrome. Am J Respir Crit Care Med 2002, 165:11821186.

14. Rouby JJ: Lung overinflation. The hidden face of alveolar recruitment. Anesthesiology 2003, 99:2-4.

15. Berggren $P$, Lachmann B, Curstedt T, Grossmann G, Robertson $B$ : Gas exchange and lung morphology after surfactant replacement in experimental adult respiratory distress syndrome induced by repeated lung lavage. Acta Anaesthesiol Scand 1986, 30:321-328.

16. Hafner D, Germann PG, Hauschke D: Effects of rSP-C surfactant on oxygenation and histology in a rat-lung-lavage model of acute lung injury. Am J Respir Crit Care Med 1998, 158:270-278.

17. Steinberg J, Schiller HJ, Halter JM, Gatto LA, Dasilva M, Amato M, McCann UG, Nieman GF: Tidal volume increases do not affect alveolar mechanics in normal lung but cause alveolar overdistension and exacerbate alveolar instability after surfactant deactivation. Crit Care Med 2002, 30:2675-2683.

18. Spragg RG, Smith RM, Harris K, Lewis J, Hafner D, Germann P. Effect of recombinant SP-C surfactant in a porcine lavage model of acute lung injury. $J$ Appl Physio/ 2000, 88:674-681.
19. Martynowicz MA, Minor TA, Walters BJ, Hubmayr RD: Regional expansion of oleic acid-injured lungs. Am J Respir Crit Care Med 1999, 160:250-258.

20. Martynowicz MA, Walters BJ, Hubmayr RD: Mechanisms of recruitment in oleic acid-injured lungs. J App/ Physiol 2001, 90:1744-1753.

21. DiRocco JD, Pavone LA, Carney DE, Lutz CJ, Gatto LA, Landas SK, Nieman GF: Dynamic alveolar mechanics in four models of lung injury. Intensive Care Med 2006, 32:140-148.

22. Puybasset L, Cluzel P, Chao N, Slutsky AS, Coriat P, Rouby JJ: A computed tomography scan assessment of regional lung volume in acute lung injury. The CT Scan ARDS Study Group. Am J Respir Crit Care Med 1998, 158:1644-1655.

23. Vieira SR, Puybasset L, Lu Q, Richecoeur J, Cluzel P, Coriat P, Rouby JJ: A scanographic assessment of pulmonary morphology in acute lung injury. Significance of the lower inflection point detected on the lung pressure-volume curve. Am J Respir Crit Care Med 1999, 159:1612-1623.

24. Puybasset L, Gusman P, Muller JC, Cluzel P, Coriat $P$, Rouby JJ: Regional distribution of gas and tissue in acute respiratory distress syndrome. III. Consequences for the effects of positive end-expiratory pressure. CT Scan ARDS Study Group. Adult Respiratory Distress Syndrome. Intensive Care Med 2000, 26:1215-1227.

25. Terragni PP, Rosboch G, Tealdi A, Corno E, Menaldo E, Davini O, Gandini G, Herrmann P, Mascia L, Quintel M, Slutsky AS, Gattinoni L, Ranieri VM: Tidal hyperinflation during low tidal volume ventilation in acute respiratory distress syndrome. Am J Respir Crit Care Med 2007, 175:160-166.

26. Haitsma JJ, Lachmann RA, Lachmann B: Open lung in ARDS. Acta Pharmacol Sin 2003, 24:1304-1307.

27. Rouby JJ, Puybasset L, Nieszkowska A, Lu Q: Acute respiratory distress syndrome: lessons from computed tomography of the whole lung. Crit Care Med 2003, 31:S285-S295.

28. Rouby JJ, Lu Q: Bench-to-bedside review: adjuncts to mechanical ventilation in patients with acute lung injury. Crit Care 2005, 9:465-471.

29. Gattinoni L, Caironi $P$, Cressoni M, Chiumello D, Ranieri VM, Quintel M, Russo S, Patroniti N, Cornejo R, Bugedo G: Lung recruitment in patients with the acute respiratory distress syndrome. N Engl J Med 2006, 354:1775-1786.

30. Suter PM, Fairley B, Isenberg MD: Optimum end-expiratory airway pressure in patients with acute pulmonary failure. $N$ Engl J Med 1975, 292:284-289. 